\title{
WEAR PERFORMANCE OF Al 6061 POST HEAT TREATMENT
}

\author{
RAGHU $\mathbf{N}^{1}$, N JAYASHANAKAR ${ }^{2} \&$ V CHANDAN ${ }^{3}$ \\ ${ }^{1,3}$ Assistant Professor, Department of Mechanical Engineering, Vidyavardhaka College of Engineering, Mysuru, India \\ ${ }^{2}$ Associate Professors, Department of Mechanical Engineering, Vidyavardhaka College of Engineering, Mysuru, India
}

\begin{abstract}
Aluminium Alloy 6000 series has found a wide range of applications in the aerospace, automobile sector in the past decades. With the idea of increasing its performance heat treatment studies on 6061 aluminium alloy is been conducted. The main focus of the this study is to find the effect of heat treatment with different cooling procedure such as air cooled, furnace cooled and gas quenched on mechanical, wear behavior. It was found that strength of heat treated samples has decreased considerably whereas ductility varied with different heat treatment. Hardness of the heat treated samples had considerably decreased. Wear rate of gas quenched samples has increased significantly.

KEYWORDS: Heat Treatment, Wear Performance, Al6061
\end{abstract}

Received: Jun 08, 2020; Accepted: Jun 28, 2020; Published: Aug 29, 2020; Paper Id.: IJMPERDJUN2020962

\section{INTRODUCTION}

There has been an amazing mechanical enthusiasm for Aluminum combinations since $66 \%$ of all removed things are made of aluminum and $90 \%$ of those are delivered utilizing 6 XXX mixes. AA6061 is one of the most extensively used aggravates, these materials can be heat rewarded to convey precipitation to various degrees [1]. The mechanical properties of the 6xxx aluminum mixes in the T6 tempers are unequivocally depending upon the substance blend. The 6xxx aluminum mixes are commonly used as expelled things, similarly with respect to advancement and automobile application. The straightforwardness with which these mixes can be formed, their low thickness, there by and large amazing disintegration and surface properties and incredible weldability are factors that alongside a low worth these make them financially very engaging [2].

The 6000 course of action composites containing $\mathrm{Cu}, \mathrm{Mg}$, and $\mathrm{Si}$ are somewhat logically obfuscated to control, considering precipitation of the age-hardening stages during creation. It is critical to control the methods of scattered and quicken course of action so as to get the perfect quality, grain size, and crystallographic surface in the last sheet. These blends moreover offer a low plan remunerated quality for high porousness, got together with quick age setting to a modestly high caliber in the formed part during the during the paint prepare cycle [3]. The structure of essential aerospace amalgams is on a very basic level dependent on improving quality and malleability, the two of which can be redesigned by controlling the alloying segment increments similarly as heat treatment conditions [4]. The best nature of the weld can be practiced by post weld treatment and developing which realized uniform precipitation all through the weld, HAZ and base metals [5].

Cryorolled Al compounds 6061 displays an improved quality and hardness when contrasted with their mass $\mathrm{Al}$ amalgams. This is a direct result of the nearness of higher convergence of solute substance $(\mathrm{Mg}$ and $\mathrm{Si})$ in the 6061 amalgam builds the quality by either in part sticking the disengagements and hindering their movement or 
by impeding the separation obliteration during distortion, bringing about upgrading separation thickness and separation connections. The hardness estimations of cryorolled $6061 \mathrm{Al}$ compounds showed a comparable pattern and it is higher than that of the $6063 \mathrm{Al}$ composites [6].

The impact of aging heat treatment of welded joints and mechanical properties of Al 6061 shows that pre-welding age heat treatment improves the mechanical properties of welding joints. The hardness estimation of the welded tests can increment fundamentally relying upon ageing temperature and time. An increment in the hardness can be clarified with the second stage precipitation inside the matrix stage. The micro- hardness explore indicated that the most elevated hardness esteems are in the base metals of age samples [7].Compression, ductile, hardness tests done with AA 6061 under strengthened conditions uncover that manganese content controlled the grain structure which brings about greater strength [8]. Corrosion fatigue and cryogenic solidification effects on aluminium alloy can be seen from various literature available $[9,10]$. In the current examination, the mechanical and wear properties of AA6061 exposed to different heat treatment are investigated.

\section{EXPERIMENTATION}

The effect of heat treatment on AA series, namely the Al 6061flat plates was studied. Flat plates were subjected to annealing, furnace cooling, and gas quenching. Annealing was carried out at $435^{\circ} \mathrm{C}$ for 3 hours and air cooled, furnace cooling was done at $435^{\circ} \mathrm{C}$ for $3 \mathrm{hrs}$ and cooled in the furnace for 12 hours, and Gas Quenching was done by heating for $435^{\circ} \mathrm{C}$ for $3 \mathrm{hrs}$ and cooled using pressurized nitrogen gas.Tensile test was performed on the above samples. From the tensile plots as shown in figure 1, the heat treated $\mathrm{Al} 6061$ had reduced peak strength by almost 50\% compared to untreated sample. The percentage of elongation was highest during furnace cooled at $6 \%$ and almost the same for annealing and had reduced for gas quenched at $50 \%$ compared to untreated sample.

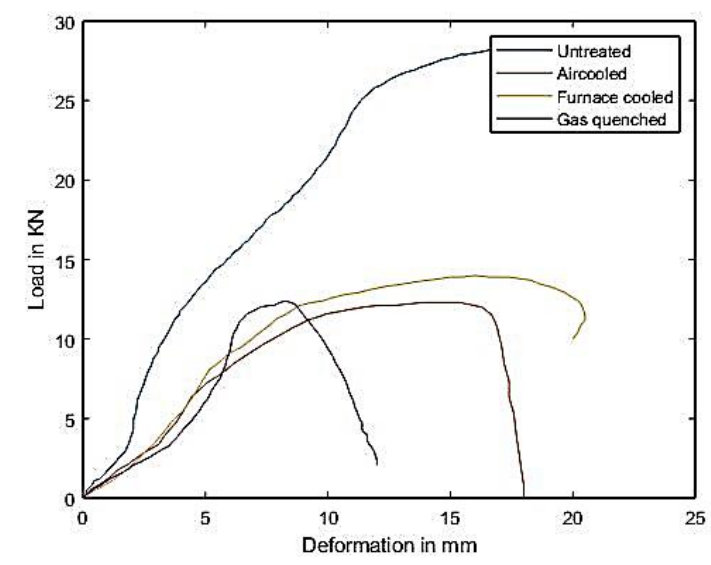

Figure 1: Tensile Plot. 


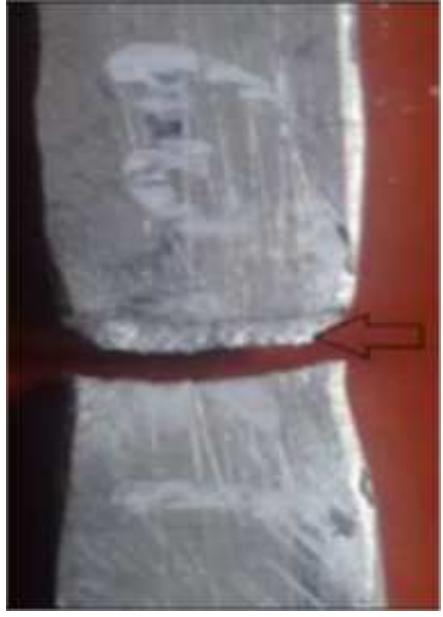

Figure 2a: Untreated

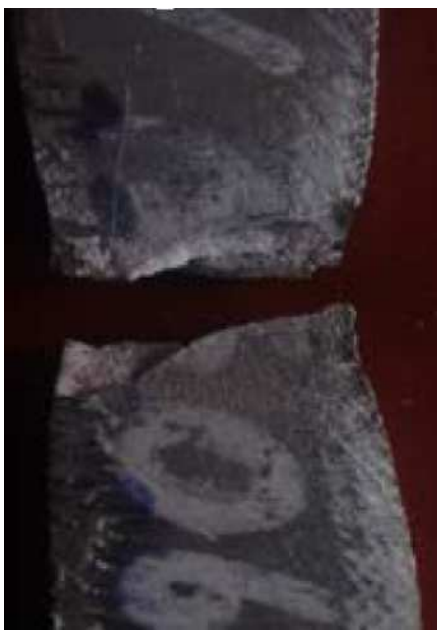

Figure 2c: Gas Quenched

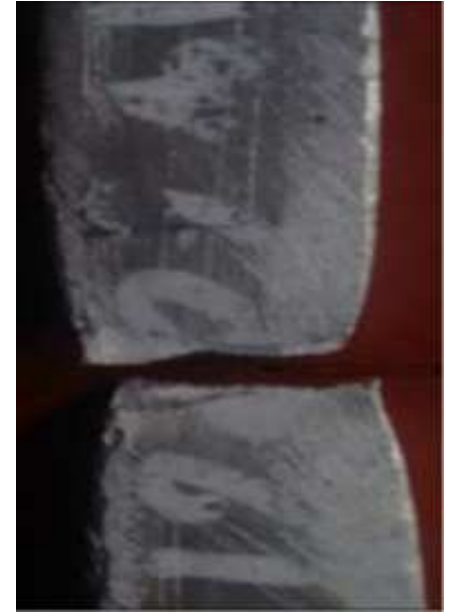

Figure 2b: Air Quenched

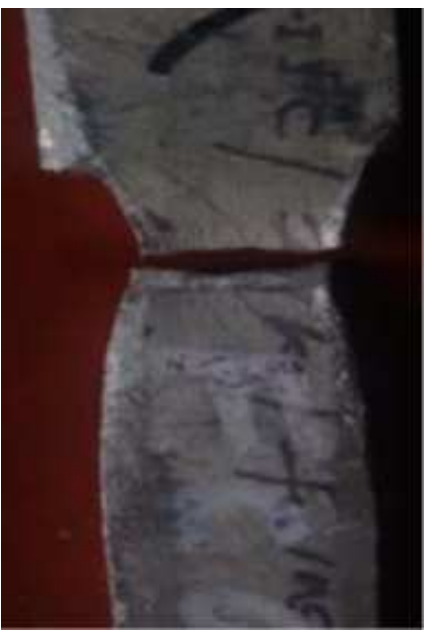

Figure 2d: Furnace Cooled

Figure 2: Fractured Tensile Samples.

The fractured samples from the tensile test are as shown in figure2;it was observed that the untreated $\mathrm{Al} 6061$ showed cup and cone type of fracture. The air and gas quenched followed a catastrophic failure with no evidence of stretch or elongation. The fracture was associated with a sudden noise; the fractured edge revealed to be sharp and illustrates the severity of stress accumulation on the edges. Perhaps few specimens resulted in failure at the grip surface.

The average BHN hardness values of the specimen were 100.5, 32.64, 38.63, and 37.16 correspondingly for untreated, furnace cooled, gas quenched and air cooled. A dry sliding wear test was conducted on the specimen with dimension 50x6. 35x6.35mm. All tests were conducted at $400 \mathrm{rpm}, 80 \mathrm{~mm}$ track diameter for $3 \mathrm{~min}$ at two loads of $5 \mathrm{~kg}$ and $7 \mathrm{~kg}$. Wear parameters like material loss, frictional force was calculated. Material loss was measured using the weight loss method. The average values of weight loss and friction force are as tabulated below. 
Table 1: Weight Loss and Friction Force of Untreated and Heat Treated Samples

\begin{tabular}{|l|c|c|}
\hline \multicolumn{1}{|c|}{ Material } & Weight loss in grams & Friction force in Newton \\
\hline Untreated & 0.0345 & 16.525 \\
\hline Air Quenched & 0.042 & 20.105 \\
\hline Gas Quenched & 0.016 & 16.94 \\
\hline Furnace Cooled & 0.026 & 17.465 \\
\hline
\end{tabular}

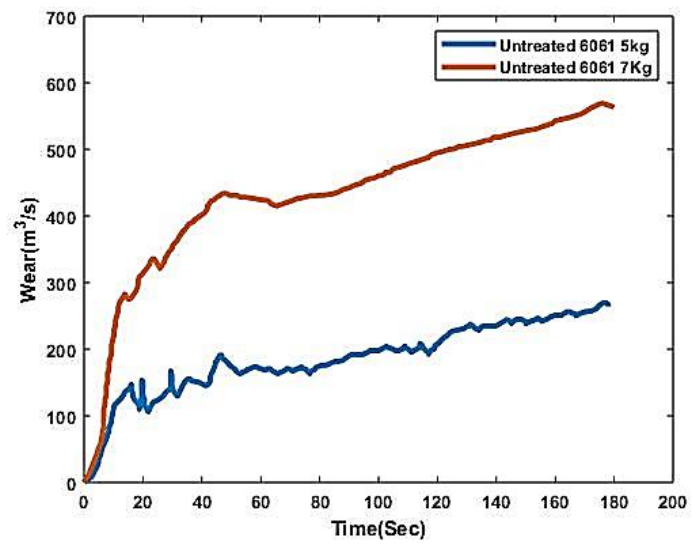

Figure 3a: Untreated AA 6061

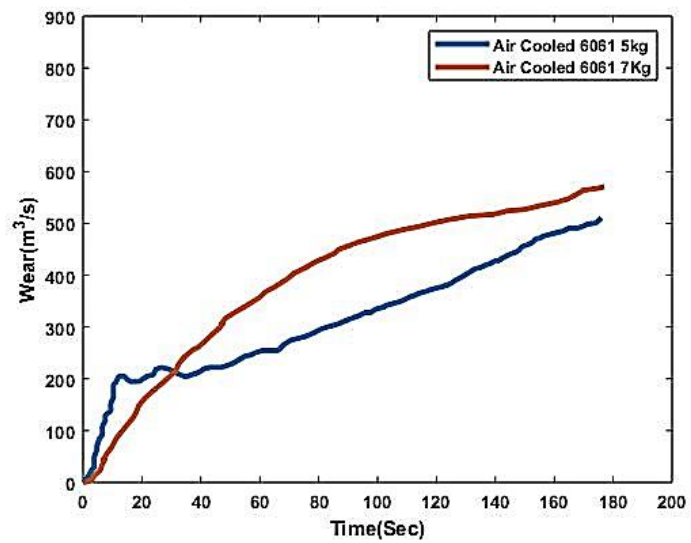

Figure 3c: Air Quenched AA 6061

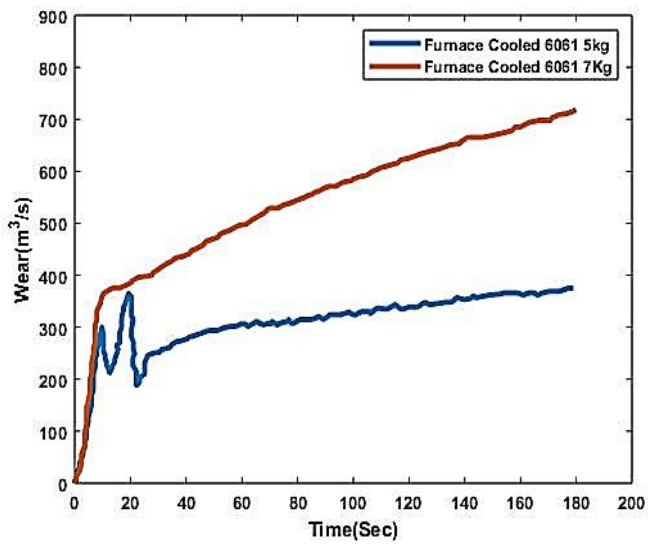

Figure 3b: Furnace Cooled AA 6061

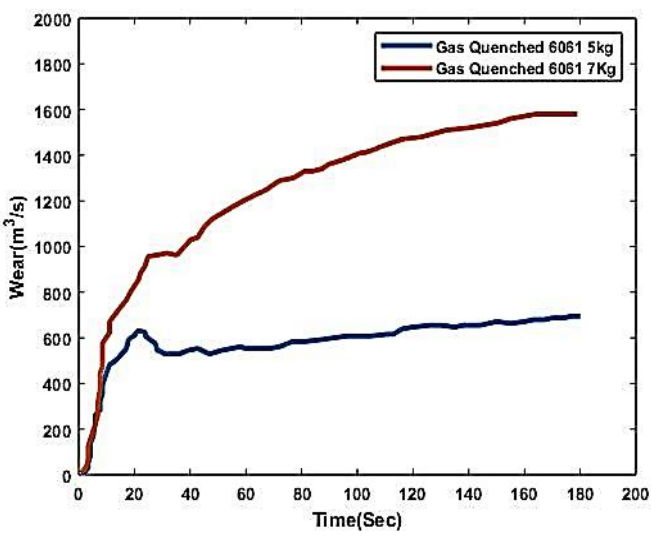

Figure 3d: Gas Quenched AA 6061

Figure 3: Wear Characteristics of Untreated and Heat Treated Samples.

Plots from figure 3 indicated that the wear diminished as the stacking condition diminished. It is seen that as the loading changed from $5 \mathrm{~kg}$ to $7 \mathrm{~kg}$, there was an expansion in wear rate. For untreated Al6061 at $7 \mathrm{~kg}$ the wear increases linearly to some extent with time, then the fluctuation in the wear take place, then to increase of time there is a rapid increase in the wear has seen in the graph. For $5 \mathrm{~kg}$ load the wear increases linearly and staggered variation in the in the wear with time, again the wear increases gradually with time has seen. For furnace cooled 6061 aluminium alloy for $7 \mathrm{~kg}$ load rapid linear increase in the wear with time and then the gradual increase in the wear has seen with increase with time. 
For $5 \mathrm{~kg}$, the wear increases linearly for some extent and then fluctuation in the wear take place and then again the wear progressive increase in the wear with time has seen. In case of $7 \mathrm{~kg}$ air quenched heat treatment the wear increases linearly with increase in time has seen. For $5 \mathrm{~kg}$ the wear increases linearly for some extent, then again fluctuation in the wear takes place again the wear increases linearly with time has seen.

For gas quenched heat treatment $7 \mathrm{~kg}$ aluminium alloy the wear increases progressively with time has seen. For $5 \mathrm{~kg}$ load the linear increase in the war has seen with time to some extent, then again the wear increases gradually with time. For $5 \mathrm{~kg}$ load, wear increases $47 \%$, 28\%, 60.85\% for air quench, furnace cool, gas quench respectively when compared with untreated aluminium alloys. For $7 \mathrm{~kg}$ load, wear increases $0.52 \%, 21 \%, 64.46 \%$ for air quench, furnace cool, and gas quench respectively when compared with untreated aluminium alloys.

\section{CONCLUSIONS}

The investigation on aluminium alloys Al6061with heat treatment and uncovered example results that the hardness of Al6061 diminishes and it becomes milder when it is water quenched. The examinations show higher hardness in aluminum amalgam without heat treatment. Strength of heat treated sample is reduced. Percentage of elongation had varied with respect to heat treatment, furnace cooled specimens showed an increased percentage of elongation. Untreated specimens showed cup and cone facture, while air and gas quenched showed stress accumulation at edges. Wear decreased as the loading condition decreased. The load increased from $5 \mathrm{~kg}$ to $7 \mathrm{~kg}$, there was an increase in wear rate. At lower and higher loadswear increases for heat treated samples when compared with untreated aluminium alloys, at both loads wear was maximum for gas quenched samples.

\section{REFERENCES}

1. Ozturk $F$ et al, (2010). Influence of aging treatment on mechanical properties of 6061 aluminum alloy. Materials \& Design, 31(2), 972-975.

2. Mrówka-Nowotnik, G. (2010). Influence of chemical composition variation and heat treatment on microstructure and mechanical properties of 6xxx alloys. Archives of materials science and engineering, 46(2), 98-107.

3. Burger, G. B., et al, (1995). Microstructural control of aluminum sheet used in automotive applications. Materials Characterization, 35(1), 23-39.

4. Alavala, CHENNAKESAVA R. "Effect of Temperature, Strain Rate and Coefficient of Friction on Deep Drawing Process of 6061 Aluminum Alloy." International Journal of Mechanical Engineering 5.6 (2016): 11-24.

5. Ibrahim, et al, (2014). A preliminary study on optimizing the heat treatment of high strength Al-Cu-Mg-Zn alloys. Materials \& Design, 57, 342-350.

6. Priya, R., et al, (2009). Effect of post weld heat treatment on the microstructure and tensile properties of dissimilar friction stir welded AA 2219 and AA 6061 alloys. Transactions of The Indian Institute of Metals, 62(1), 11-19.

7. Panigrahi, S. K, et al, (2008). A comparative study on mechanical properties of ultrafine-grained Al 6061 and Al 6063 alloys processed by cryorolling. Transactions of the Indian Institute of Metals, 61(2), 159-163.

8. Cicek, V. O. L. K. A. N., and M. E. H. M. E. T. Ozdemir. "Characterization Studies of Aqueous Immersion Solutions of Novel Environmentally Friendly Organometallic Corrosion Inhibitors used to Cure Aluminum 2024, 6061, AND 7075 Alloys Substrates in Corrosive Media." International J. of General Engineering and Technology (IJGET), 2 (2), 116 (2013). 
9. Sevim, I., et al, (2013). The study of MIG weldability of heat-treated aluminum alloys. The International Journal of Advanced Manufacturing Technology, 66(9-12), 1825-1834.

10. Venkateshwarlu, G., et al, (2014). Evaluation of mechanical properties of Aluminium Alloy AA 6061 (HE-20). International Journal of Current Engineering and Technology, 2, 295-7.

11. Harsha, M. L., et al, Corrosion-Fatigue Characteristics of 4043 Aluminium Alloy.

12. Resan, Kadhim K., et al. "Influence of Temperature on Fatigue Life for Friction Stir Welding of Aluminum Alloy Materials." International Journal of Mechanical \& Mechatronics Engineering IJMME-IJENS 18.02 (2018).

13. Raghu N, et al, (2018). Development \& Property Evaluation of Cryogenically Solidified Metal Matrix Composites. International Journal for Scientific Research \& Development, 6, 1866-1873.

14. Al-Zubaidi, Diyaa HJ, Muhannad Al-Waily, and Emad Q. Hussein. "Analytical investigation of crack depth and position effect onto beam force vibration response with various harmonic frequency influence." International Journal of Energy and Environment 11.1 (2020): 1-28. 